Supporting Information

\title{
Reversible CO Dissociation of Tricarbonyl Iodide [Fe]-hydrogenase Models Ligating Acylmethylpyridyl Ligands
}

Bowen Hu, Xiangyang Chen, ${ }^{+}$Dawei Gong, ${ }^{\dagger}$ Wen Cui, Xinzheng Yang *t and Dafa Chen ${ }^{\dagger}{ }^{\dagger}$

${ }^{\dagger}$ MIIT Key Laboratory of Critical Materials Technology for New Energy Conversion and Storage, School of Chemistry and Chemical Engineering, Harbin Institute of Technology

* Beijing National Laboratory for Molecular Sciences, State Key Laboratory for Structural Chemistry of Unstable and Stable Species, Institute of Chemistry, Chinese Academy of Sciences, Beijing 100190, P.R. China.

"University of Chinese Academy of Sciences

E-mail:dafachen@hit.edu.cn; xyang@iccas.ac.cn 


\section{IR spectra}

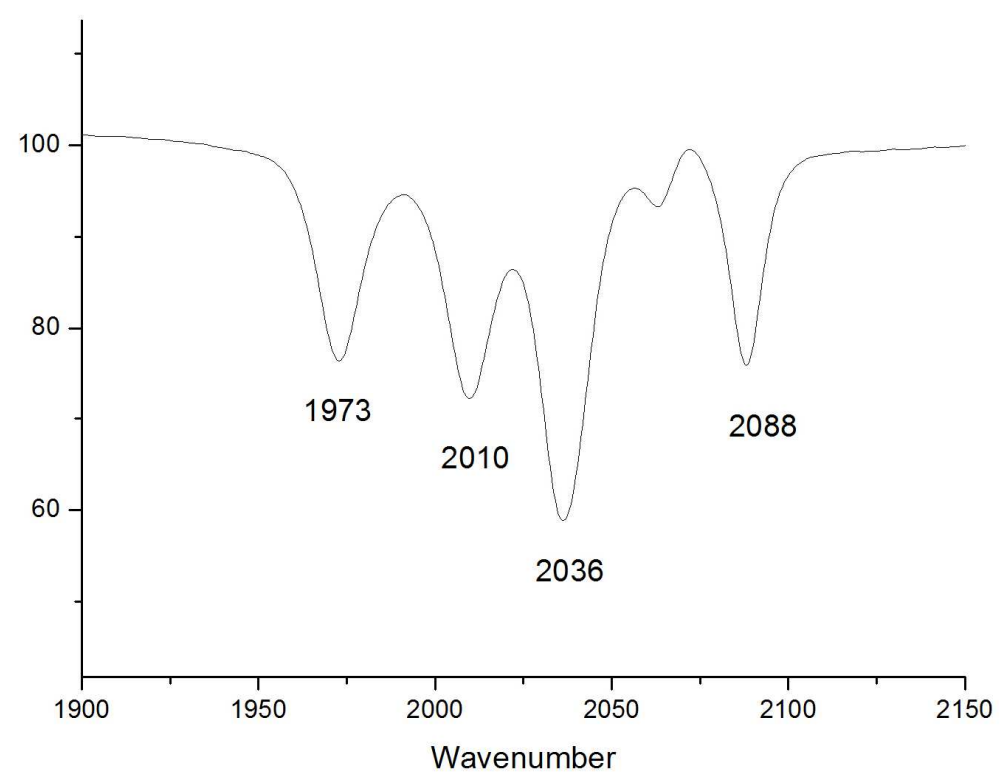

Figure S1. IR spectrum of $\mathbf{3}$ in $\mathrm{CH}_{3} \mathrm{CN}$. 


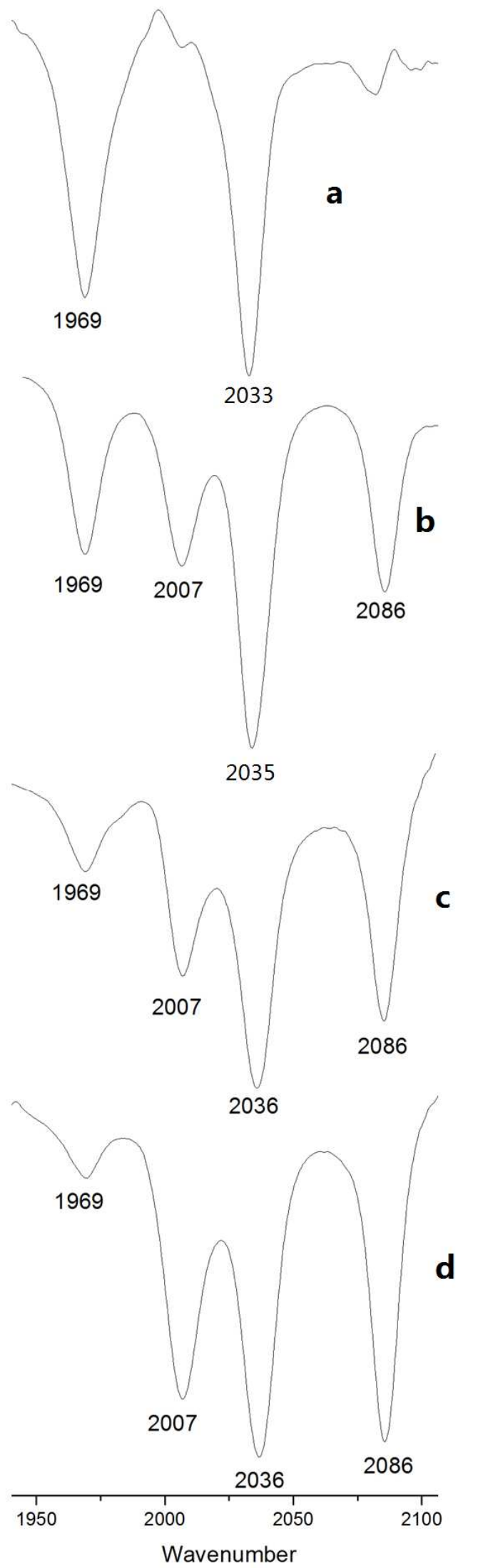

Figure S2. IR spectra: (a), 6 in acetone; (b), 6 in acetone for 1h; (c), 6 in acetone for 3h; (d), 3 in acetone. 


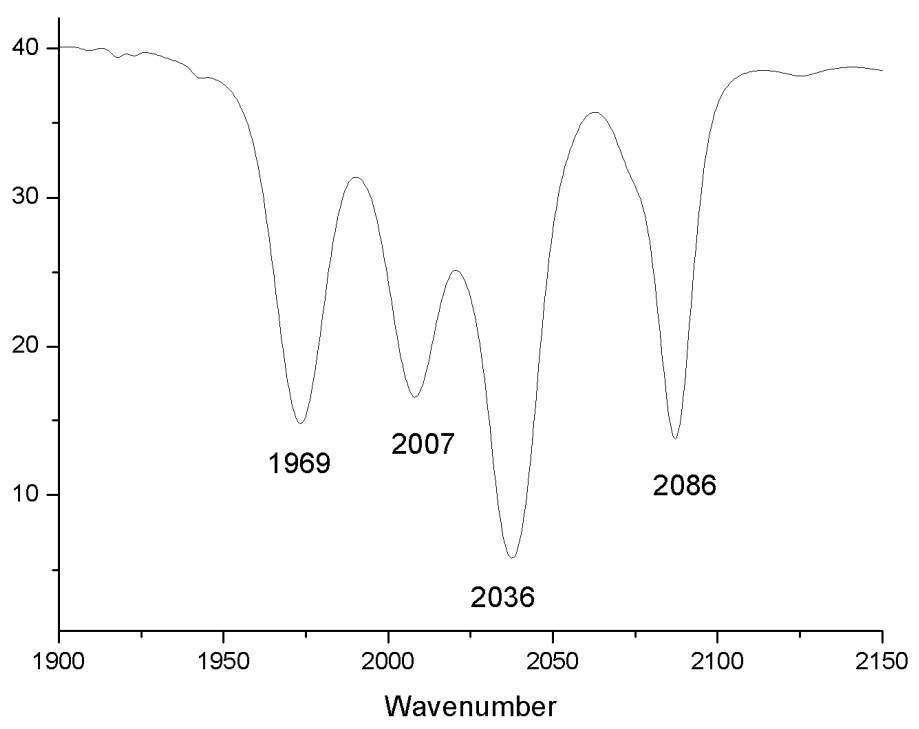

Figure S3. IR spectrum of $\mathbf{3}$ and $\mathbf{6}$ in acetone.

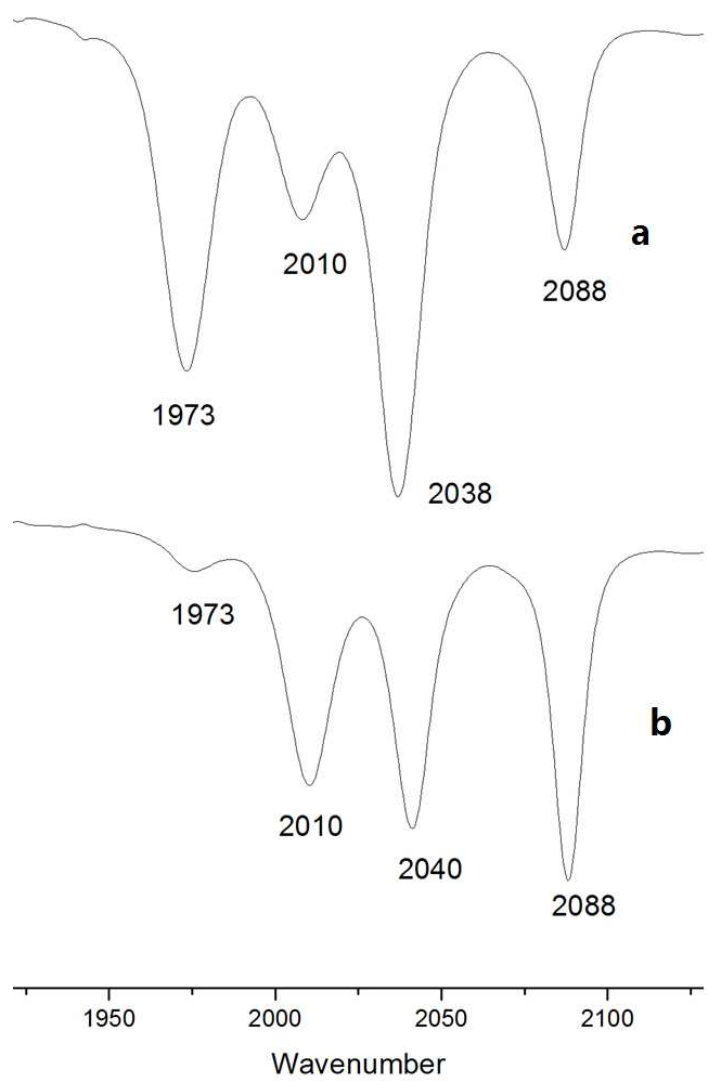

Figure S4. IR spectra: (a), a mixture of 2 and 5 in $\mathrm{CH}_{2} \mathrm{Cl}_{2} ;$ (b), 2 in $\mathrm{CH}_{2} \mathrm{Cl}_{2}$. 


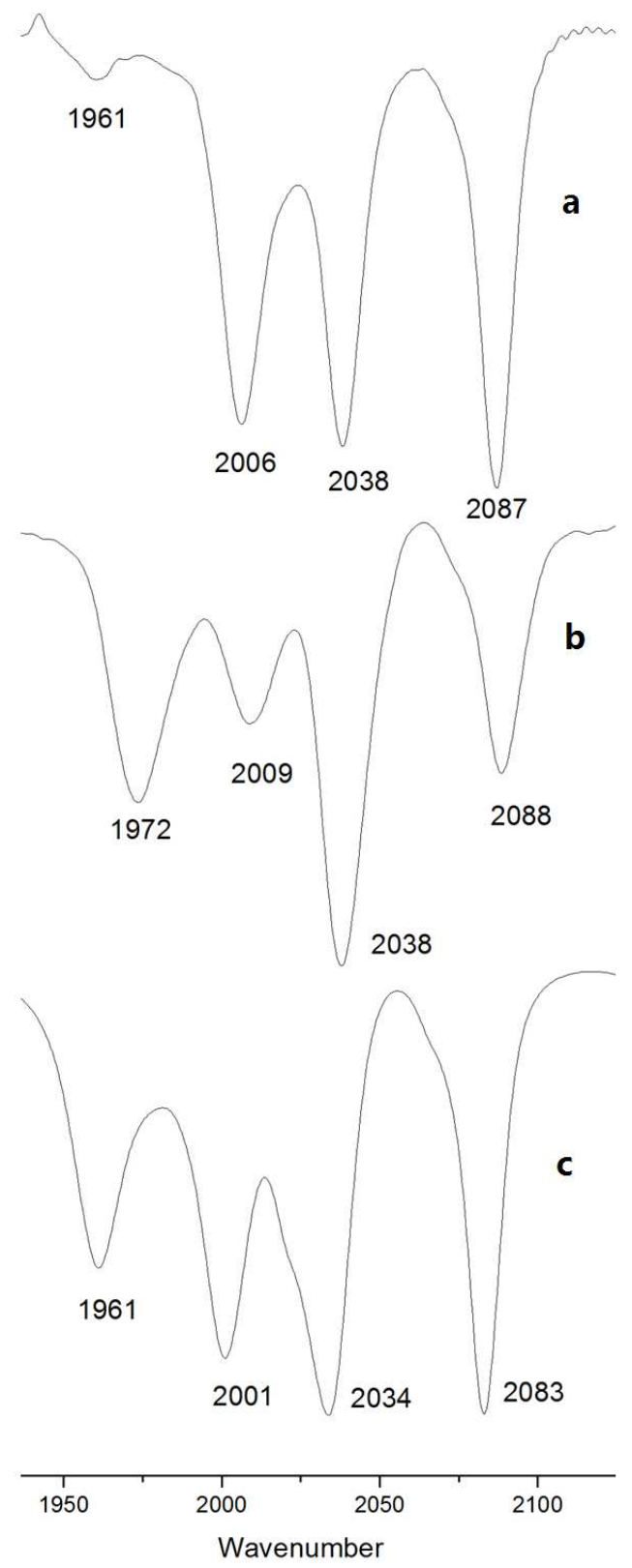

Figure S5. IR spectra of 1: (a), dissolved in acetone; (b), dissolved in $\mathrm{CH}_{3} \mathrm{OH}$; (c) dissolved in THF. 


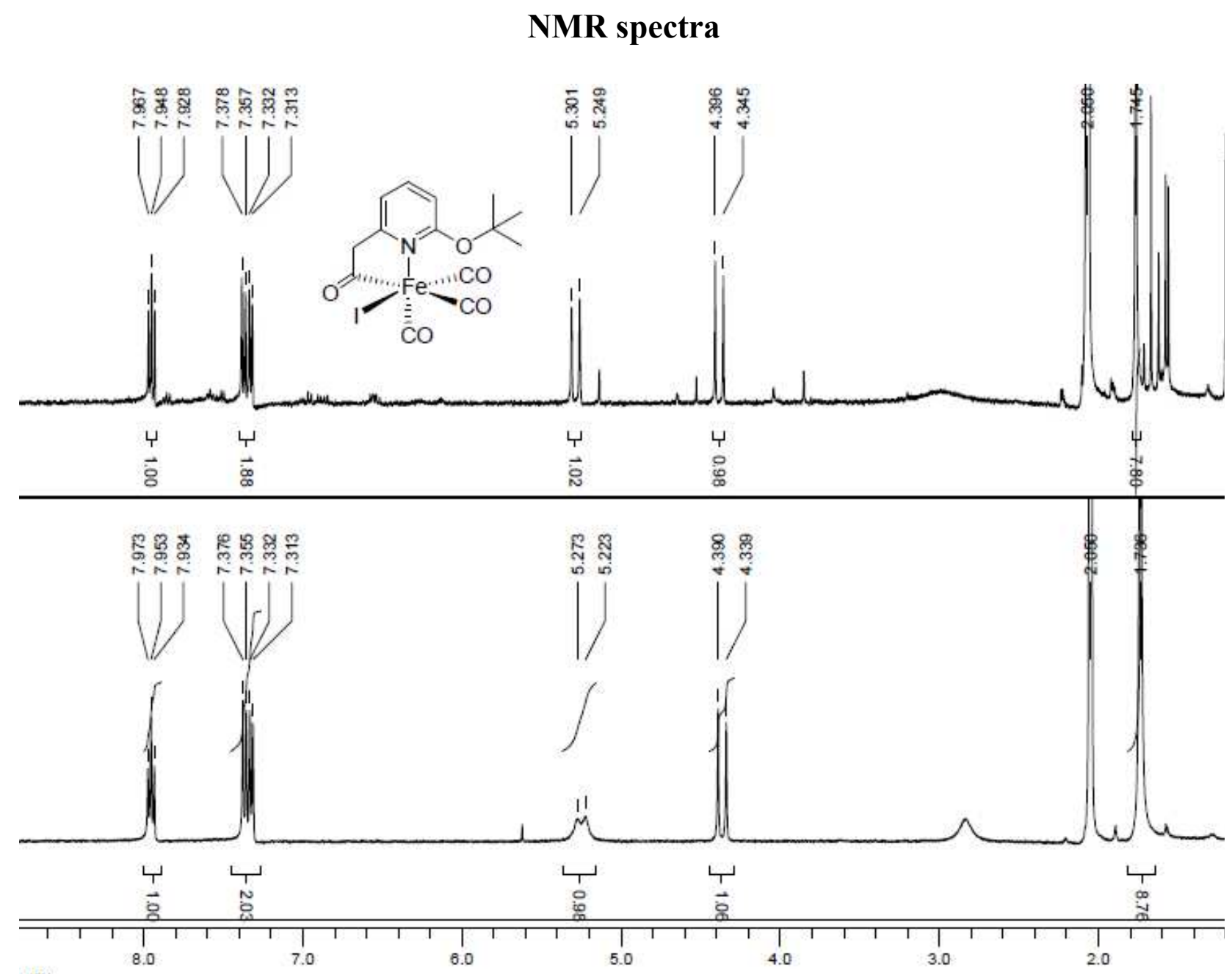

Figure S6. Top: ${ }^{1} \mathrm{H}$ NMR spectrum of a solution of 6 dissolved in $\mathrm{D}_{6}$-acetone for $24 \mathrm{~h}$; bottom: pure 3 . (From these two spectra, $\mathbf{6}$ almost converted back to $\mathbf{3}$ completely, except some decomposition) 

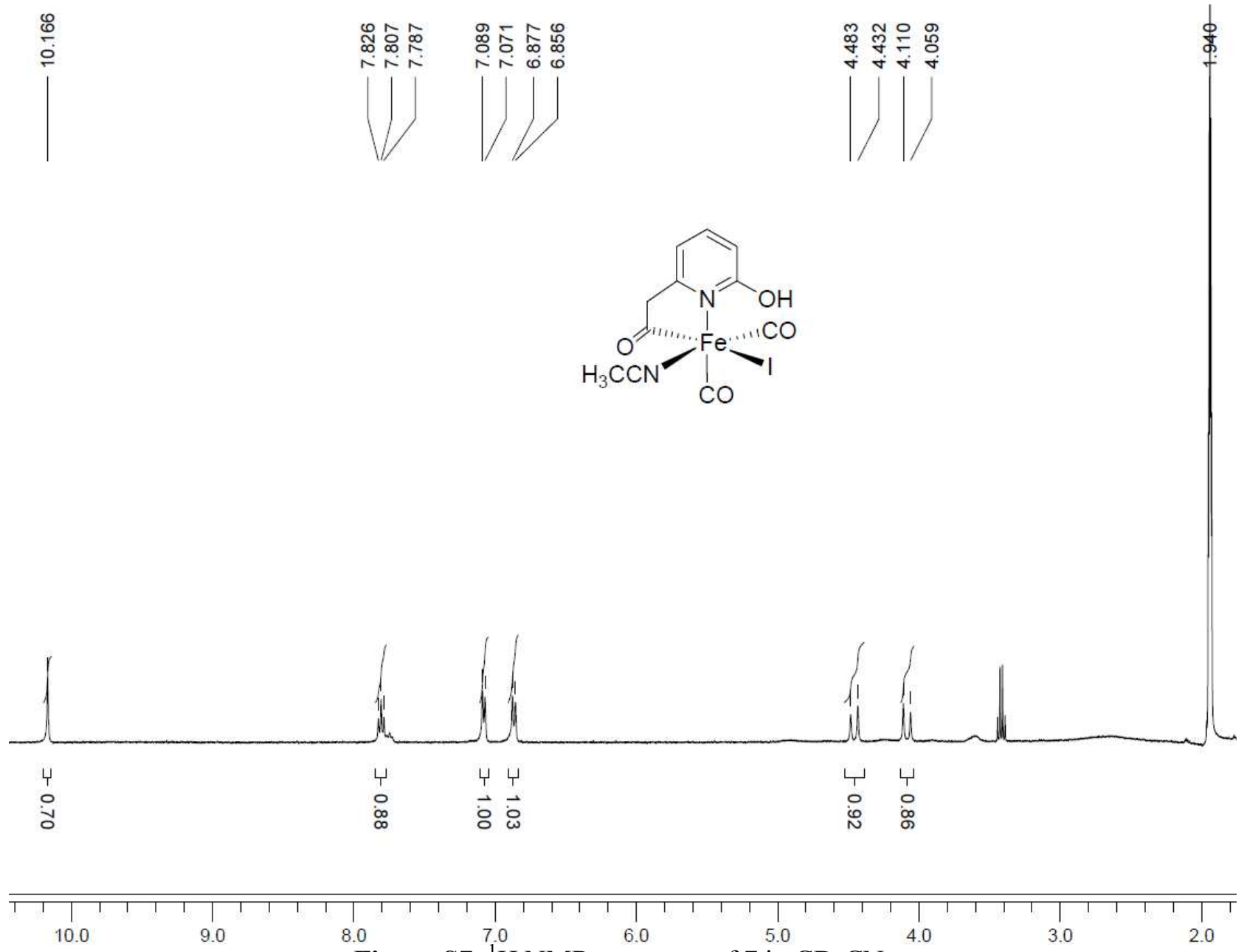

Figure S7. ${ }^{1} \mathrm{H}$ NMR spectrum of 7 in $\mathrm{CD}_{3} \mathrm{CN}$. 

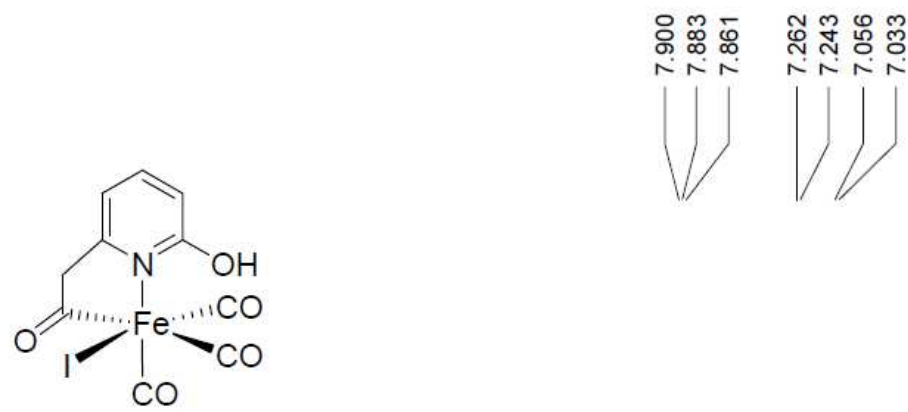

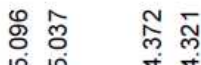

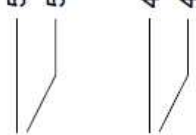

1

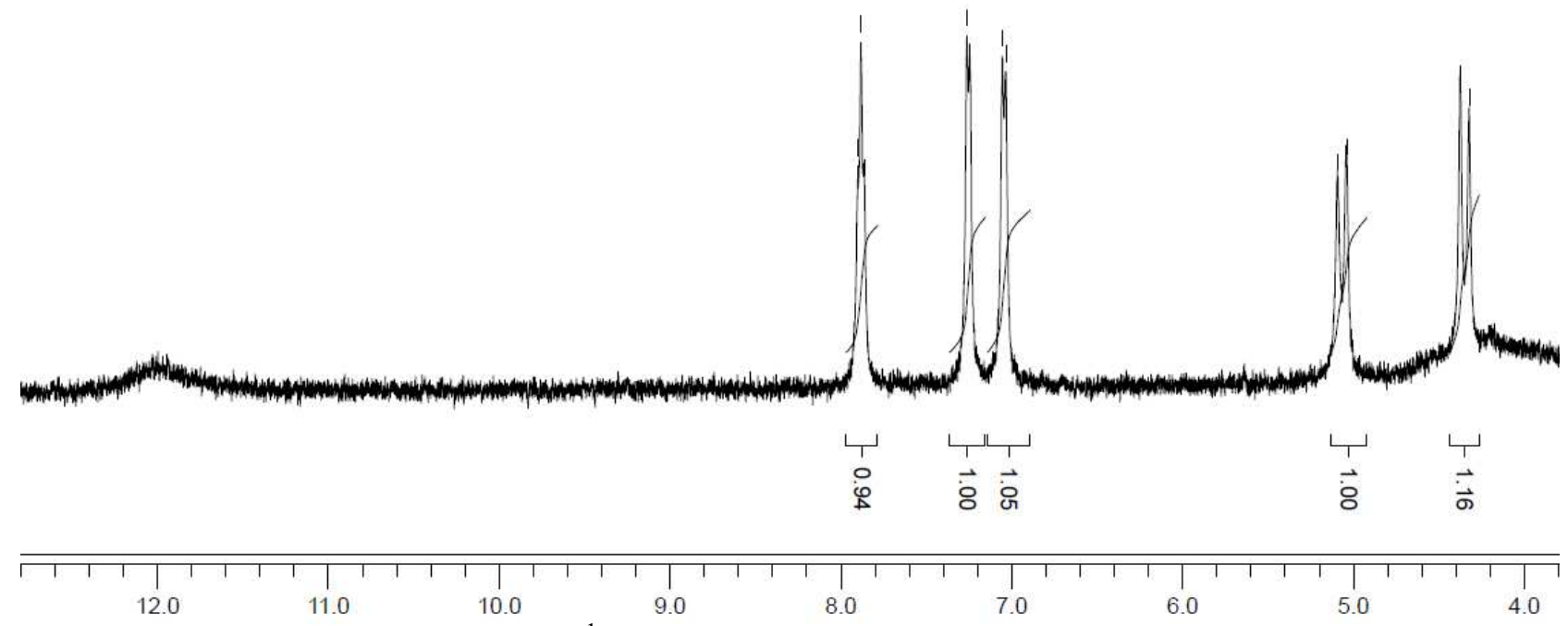

Figure S8. ${ }^{1} \mathrm{H}$ NMR spectrum of $\mathbf{1}$ in $\mathrm{D}_{6}$-acetone. 


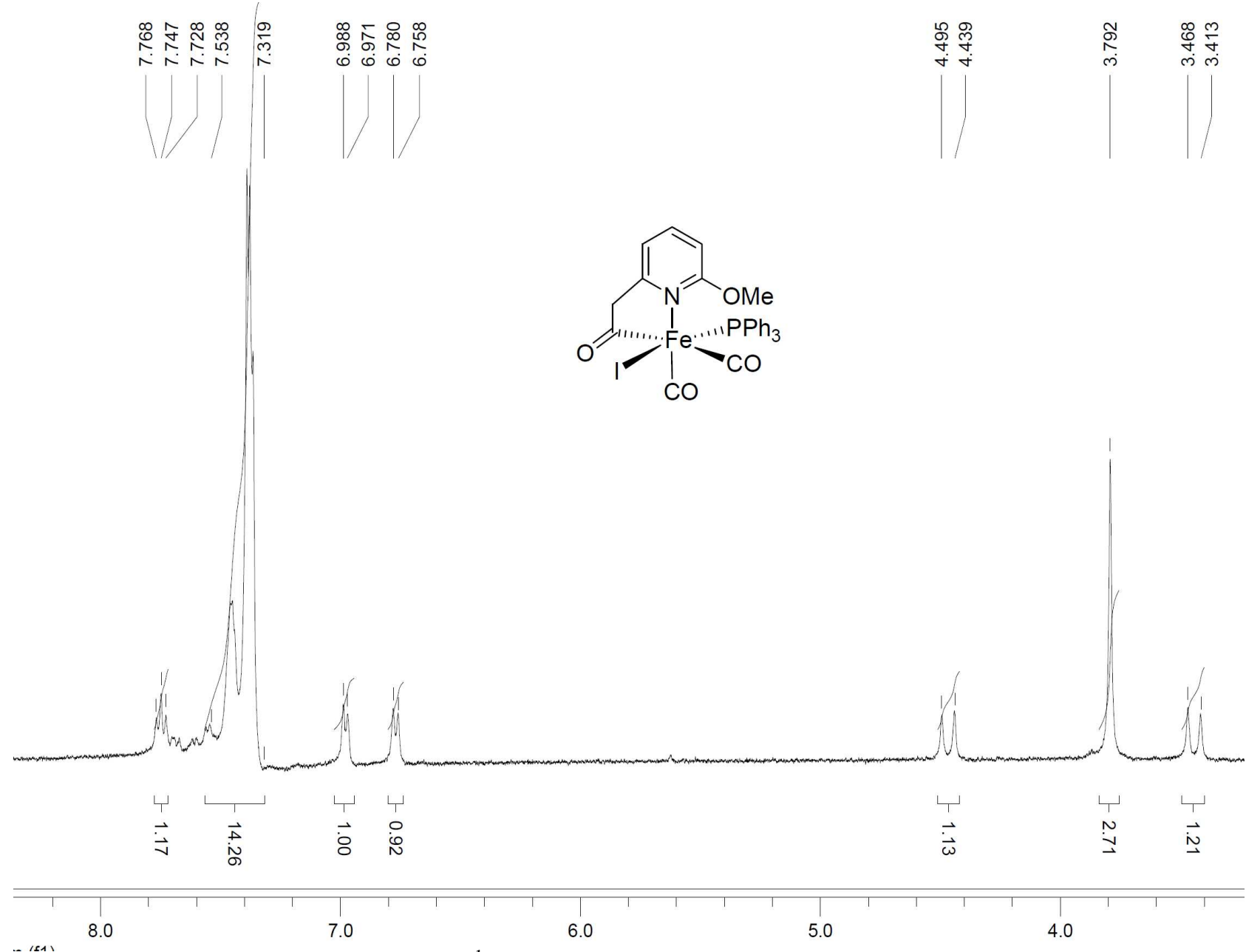

Figure S9. ${ }^{1} \mathrm{H}$ NMR spectrum of $\mathbf{8}$ in $\mathrm{D}_{6}$-acetone. 
<smiles></smiles>

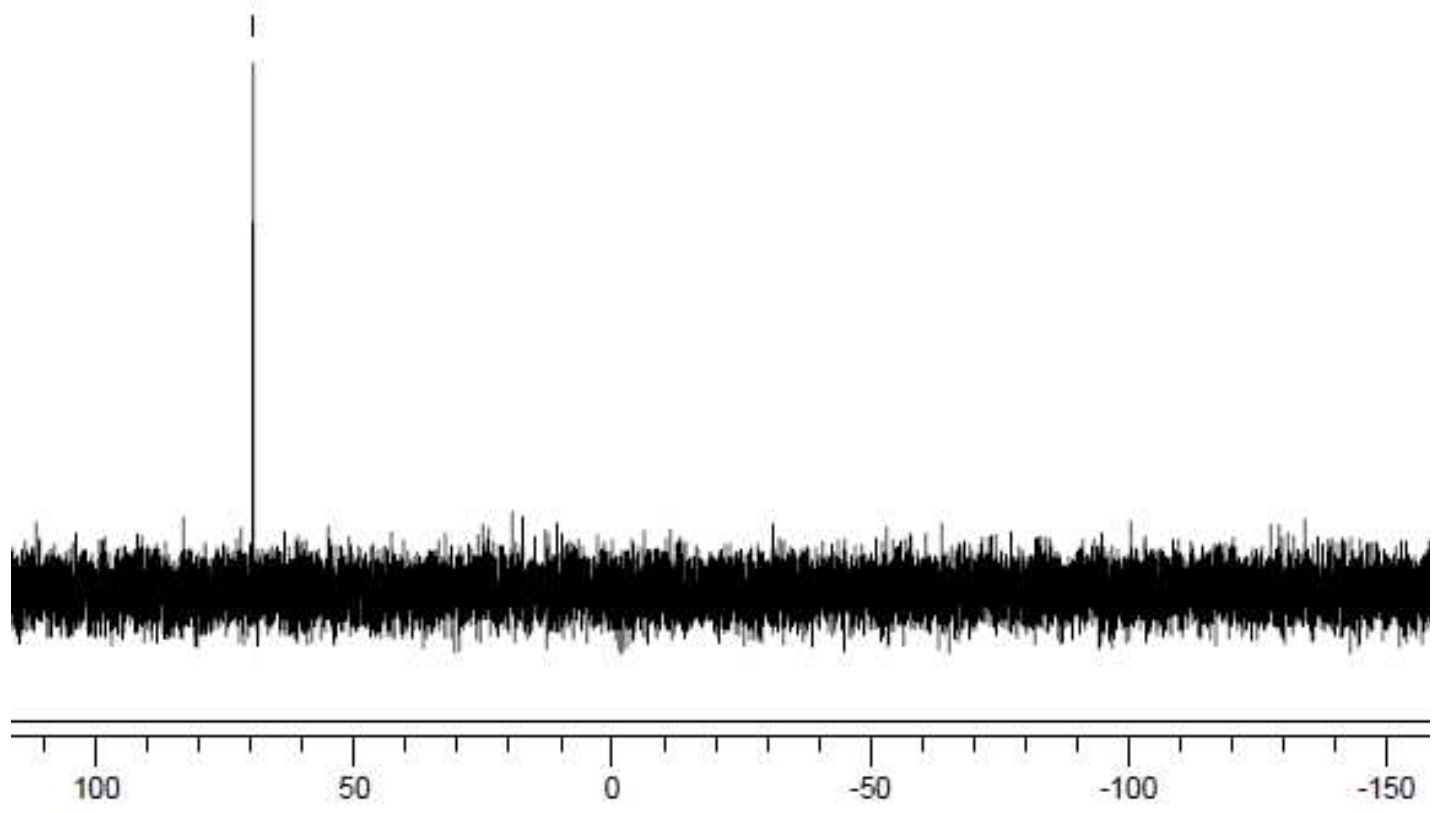

Figure S10. ${ }^{31} \mathrm{P}$ NMR spectrum of 8 in $\mathrm{D}_{6}$-acetone. 